\title{
COMPETITION LAW AND PHARMA: AN ECONOMIC PERSPECTIVE
}

\section{Benoît Durand}

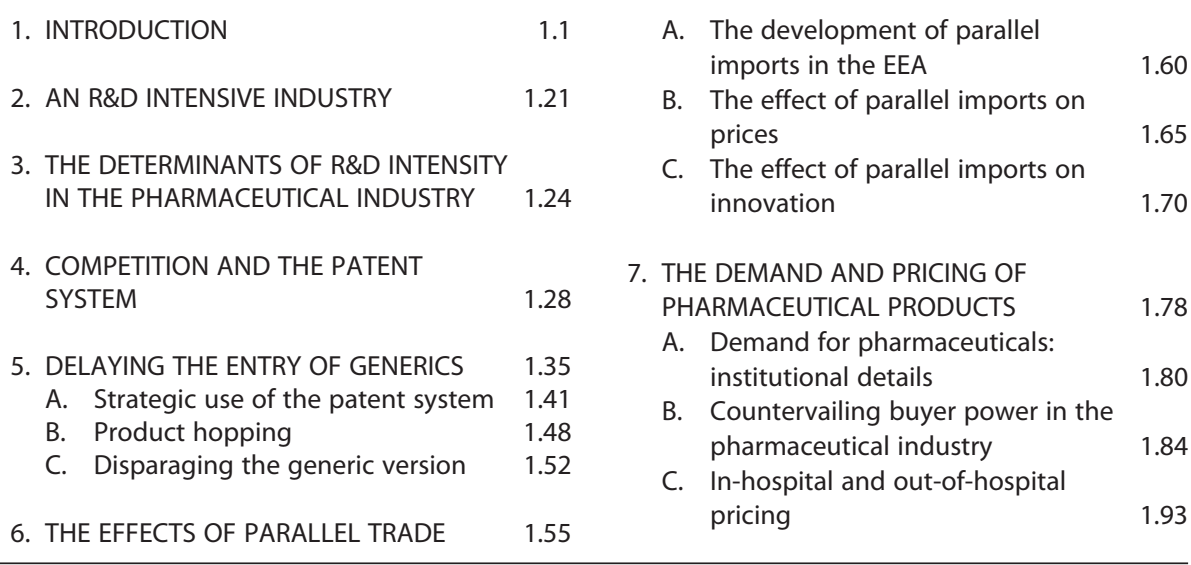

\section{INTRODUCTION}

The pharmaceutical industry has been under the scrutiny of competition

watchdogs. In 2009, the European Commission published the final report of its Sector Inquiry, in which it laid out a number of concerns about the state of competition. In particular, the Commission found that some practices of originator companies had the objective or effect of stifling competition, notably against generics. Since 2009 , the Commission but also some National Competition Authorities have stepped up enforcement activities in this sector, justifying notably their intervention by the need to keep public health budgets under control and to maintain widespread access to affordable medicines.

The importance of the pharmaceutical industry is beyond dispute. Pharmaceutical companies have contributed to the development of medical treatments, improving human health and quality of life, and extending the human lifespan. Over the last 15 years, life expectancy at birth in the EU-28 increased 
by 2.9 years, from 77.7 to 80.6 years $(2015) .{ }^{1}$ Even though not all of this progress can be attributed to the pharmaceutical industry, it nevertheless plays a significant role in developing new treatments.

1.3 In parallel, the economic importance of the industry has also risen. The European Federation of Pharmaceutical Industries and Association (EFPIA) estimates that the size of the pharmaceutical market in Europe has grown from EUR 89 billion in 2000 to an estimated EUR 202 billion in 2016, which suggests that in 16 years, industry revenues (measured at ex-factory prices) have more than doubled. ${ }^{2}$ This size increase is due in part to the rise in the consumption of pharmaceuticals. For example, in the Organisation for Economic Co-operation and Development (OECD), between 2000 and 2015, the use of antihypertensive, antidiabetic and antidepressant medications nearly doubled, while the use of cholesterol-lowering drugs nearly quadrupled. ${ }^{3}$

1.4 Today in Europe, spending on pharmaceuticals, even though it varies across countries, is substantial. For example, in the European Union in 2014, spending ranged from 0.52 and 0.70 per cent of gross domestic product (GDP) for Luxembourg and Denmark respectively to 2.11 and 2.17 per cent for Hungary and Greece respectively. ${ }^{4}$

1.5 In light of its economic importance, it is legitimate that competition authorities monitor the state of competition of the pharmaceutical industry closely. After all, anticompetitive practices and anticompetitive mergers could have a substantial impact on economic welfare, affecting millions of European consumers. However, each economic sector has its own idiosyncrasies, and these particular features must be (and are typically) taken into account by competition authorities in their investigation. The pharmaceutical sector is no exception.

1 Eurostat: Mortality and life expectancy statistics. http://ec.europa.eu/eurostat/statistics-explained/index.php/ Mortality_and_life_expectancy_statistics\#Life_expectancy_at_birth_is_slightly_decreasing, accessed on 29 May 2018.

2 European Federation of Pharmaceutical Industries and Associations, The Pharmaceutical Industry in Figures, Key Data, 2017, page 3. www.efpia.eu/media/219735/efpia-pharmafigures2017_statisticbroch_v04-final.pdf, accessed on 28 May 2018.

3 OECD, Health at a Glance: Europe 2017, page 192. https://read.oecd-ilibrary.org/social-issues-migrationhealth/health-at-a-glance-2017_health_glance-2017-en, accessed on 28 May 2018.

4 OECD, Pharmaceutical Spending Total, Percentage of GDP, 2015, https://data.oecd.org/healthres/ pharmaceutical-spending.htm\#indicator-chart, accessed on 28 May 2018. Spending in the USA was 2.07 per cent of GDP in 2015. The data include prescription drugs and over the counter (OTC) drugs. 
The pharmaceutical industry is highly innovative, and it will stay this way so long as companies continue to have the ability and incentive to fund investment on research and development $(\mathrm{R} \& \mathrm{D})$. In Europe alone, the industry is spending billions of euros on $R \& D$ to bring new treatments. Because of the highly uncertain nature of $R \& D$ investments in this industry-there are typically many failures and few successes-and the information asymmetries between pharmaceutical firms and the financial markets, pharmaceutical companies generally have to fund their own research activities.

$\mathrm{R} \& \mathrm{D}$ investments are largely encouraged by patent protection, which grants pharmaceutical companies the exclusive right to exploit their innovation for a period of 20 years. During this period of exclusivity, the originator companies are shielded from competition by copycats- to be precise, competitors manufacturing therapeutically equivalent generic versions of the molecule. The revenue earned during the period of exclusivity serves (i) to recoup the initial investments undertaken to develop the successful drug (including the losses incurred through failed attempts), which also includes a competitive return on the cost of capital, and (ii) to finance future research to develop new treatments. In practice, however, because it takes several years to bring a medicine to the market, originators do not benefit from the full period of exclusivity granted by the patent though this is sometimes mitigated by patent extensions, as will be discussed in more detail below.

In this chapter we discuss three competition issues from an economic perspective, highlighting in particular how the specificities of the industry, notably the importance of innovation, affects the assessment of competition and market outcomes.

First, there is a tension between the short-term benefits of price competition and the long-term benefit of innovation. Price competition leads to lower prices which immediately benefit consumers. However, as profits are eroded this reduces the funds available for $R \& D$ as well as the incentive to finance $R \& D$. While this is not specific to the pharmaceutical sector, its strong focus on $\mathrm{R} \& \mathrm{D}$ renders the tension especially salient. As a result, a reduction in investments could be expected to have longer-term negative consequences in terms of innovation in the industry.

The patent system, and its various extensions specific to the pharmaceutical industry, have attempted to settle this trade-off. Under the exclusivity granted by patent protection, branded medicines are sold at a premium, enabling companies to earn "supra-competitive" profits, which serve to motivate and finance R\&D investments. When the patent protection ends, because of their 
lower prices, generic medicines, which are therapeutically equivalent, tend to acquire the largest portion of the market, eating away revenue from the originator companies. Unsurprisingly, pharmaceutical companies have an incentive to prolong the period of exclusivity to fend off competition from generics. While originator companies may seek to prolong the period of exclusivity, competition authorities have taken the stance that these practices are anticompetitive, as they deprive patients from accessing lower price medicines; inevitably, this intervention reduces the ability and incentive of companies to fund future research.

1.11 Second, there is a tension between the price setting of medicines, which varies across Member States, and the objective of market integration in Europe, which is supported by the principle of free movement of goods.

1.12 Differential pricing, also known as price discrimination, enables manufacturers to sell their products at different prices in different countries. Confronted with national regulators who exert various degrees of control on prices, pharmaceutical companies sell medicines at very different price levels across countries within the European Economic Area (EEA). A recent study compared ex-factory reference prices in Europe, Australia and New Zealand for 14 medicines, and found that for most of the selected medicines, the price of the product in the highest-priced country was at least twice the price of the medicine in the country with the lowest price. ${ }^{5}$ Such a practice leads to higher profits, which not only maintains the incentive to finance $R \& D$ but also, in the case of the pharmaceutical industry, these profits can be used to fund $R \& D$ activities. Indeed, while price disparities between countries may increase the revenues of originator companies, in turn they also contribute to the raising of funds for future research. However, parallel imports can in principle undermine firms' ability to earn revenue in high-price countries. In response, originator companies may exert some control over distributors and wholesalers to prevent the emergence of parallel imports, but these measures may be viewed as restricting trade between Member States-running counter to the objective of the single market.

1.13 The objective of market integration calls for unfettered trade movements, ultimately leading to an equalisation of prices across Member States. Parallel imports of prescription medicines from low-price countries to high-price countries would have the effect of lowering prices in the high-price country.

5 Sabine Vogler, Kate Kilpatrick and Zaheer-Ud-Din Babar, "Analysis of Medicine Prices in New Zealand and 16 European Countries” (2015) 18(4) Value in Health 484-92. 
This would seemingly benefit consumers and national health insurance organisations in the high-price countries.

In practice, though, parallel imports in the pharmaceutical industry need not always bring such a clear benefit.

(a) First, there appears to be no strong evidence that parallel imports actually reduce the price of medicine to consumers in high-price countries. Because in most countries the price of medicine is regulated, the profit of arbitrage is not passed on to consumers, but rather kept by the distribution chain. In other words, consumers still pay the same regulated price, whether the product is sold directly by the originator company, or sourced from a distributor from the low-price country.

(b) Second, to curb profit erosion in high-price countries resulting from parallel imports of prescription medicines, pharmaceutical companies may no longer supply low-price countries. Indeed, originator companies may trade off the low profits in the low-price country against the risk that parallel imports will erode the higher profits in the high-price country, and hence stop supplying the low-price country.

(c) Third, the short-term benefit of affordability in high-income countries that may result from parallel imports may come at the expense of less innovation as overall industry profits are reduced. However, fearing the reaction of pharmaceutical companies, regulators in the low-price countries may loosen price regulation, thereby cutting distributors' incentive to re-export medicines, which in turn protects innovation.

Finally, the exercise of market power, which is the primary focus of competition law investigations, requires-as in other industries-a thorough examination of the facts of each case. In the pharmaceutical sector this cannot simply hinge on whether originator companies are protected by patents. Competition authorities have the task of determining whether firms hold significant market power; that is, whether firms' exercise of market power is so large that they can be deemed dominant, and/or whether practices, agreements or mergers enable firms to acquire additional market power, thereby reaping supra-competitive profits at the detriment of consumers. By definition, a firm has market power if it finds it profitable to raise prices above marginal cost. The ability to raise prices depends on the extent to which consumers can substitute to other suppliers. In particular, this depends on consumer behaviour, that is, how consumers would react to a relative price increase. $^{6}$

6 The ability of consumers to switch between products is referred to in economics as demand side substitution. 
1.16 Because originator companies are protected by patents, at least for a period of time, they appear to hold "monopoly power" over the supply of their patented medicines. That is, patients have no alternative but to purchase the medicine that is prescribed for their treatment. Once the patent expires, generic versions become available, and the pricing power of originator companies diminishes. However, even when medicines are patented, it cannot be presumed that originator companies necessarily hold substantial market power, without examining the nature of demand.

1.17 The demand for pharmaceutical products is unusual in many respects. In general, patients do not pay for the cost of healthcare or they pay only part of the cost as medical expenses are covered by national health insurance schemes, which typically insure residents against the risk of illness. Due to the existence of medical insurance, many health care services are therefore provided to the patients at effectively zero or low monetary prices, and so the standard economic model predicts that demand should not be price sensitive. This is even more so since doctors decide the treatment and the amount of medicines that patients need, typically without regard for their cost. On this count, pharmaceutical companies should have strong pricing power.

1.18 However, in most European countries, the price of medicines that patients purchase in pharmacies is the outcome of negotiation between the national regulator and pharmaceutical companies. Because each regulator represents millions of potential patients, it should have monopsony power. That is, to sell medicines in one country, pharmaceutical companies have no choice but to negotiate with that regulator to obtain approval.

1.19 In principle, this should give that regulator strong bargaining power, putting downward pressure on prices. The reality is often more complex. The negotiating power of these regulators is weakened by the fact that (i) often they have no control over the quantities of medicines consumed since only doctors prescribe treatment and (ii) they can hardly afford to refuse to reimburse medicines that have demonstrated therapeutic value.

1.20 In sharp contrast, hospitals that negotiate directly with manufacturers can obtain better prices. Unlike national health insurance organisations, hospitals may be able to influence doctors and recommend medicines, in particular when they have a choice between patented medicines that can be used to treat the same illness. Given that they have more room to manoeuvre, hospitals may thus fully exploit competition between branded medicines (inter-brand competition) and also between the originator products and their generic version. 


\section{AN R\&D INTENSIVE INDUSTRY}

The intensity of $R \& D$ activities is one of the major features that sets apart the pharmaceutical industry from other industries. According to the European Commission, pharmaceuticals and biotech combined is one of the most intensive R\&D industries in Europe. ${ }^{7}$ EFPIA, the industry association, estimates that the pharmaceutical industry invested EUR 35,000 million in $R \& D$ in Europe in 2016. ${ }^{8}$ In 2015, investment in R\&D in the United States amounted to USD 47,051 million (or EUR 44,086 million). This clearly indicates that the European pharmaceutical industry is committed nearly as much as the American industry to the development of new medicines.

Pharmaceutical companies invest these large sums to turn fundamental research into innovative treatment, leading to new medicines for the benefit of patients. It is undisputed that innovation in human treatment is a major source of human progress. For instance, the eradication of smallpox, mostly through vaccination, has saved tens, possibly hundreds of millions of lives. ${ }^{9}$ On a different scale, the death rate from cardiovascular diseases has been steadily declining due in large part to new medicines such as cholesterol-lowering treatments. For the past 15 years, every year the US Federal Drug Administration (FDA) approved between 17 and 45 new medicines. ${ }^{10}$ Although it is difficult to quantify the welfare benefits of pharmaceutical innovations, they are likely to be vast.

Without the significant R\&D efforts of originator companies and other stakeholders (e.g., hospitals, universities and governments) the development of innovative treatment would be greatly reduced. For this reason, it is important to maintain the industry's ability and incentive to continue investing in R\&D. This point is becoming even more pressing as the cost of developing new medicines has increased considerably over time: a recent study shows the average total cost per approved new compound has increased yearly by 8.5 per

7 European Commission, JRC/DG RTD, EU Industrial RED Investment Scoreboard 2017, http://iri.jrc. ec.europa.eu/scoreboard17.html. In 2017, Pharmaceuticals \& Biotechnology was third with 13.7 per cent of R\&D intensity behind IT Hardware with 15.7 per cent and Biotechnology with 24 per cent.

8 European Federation of Pharmaceutical Industries and Associations, supra note 2.

9 World Health Organization, Smallpox, Eradicating an Ancient Scourge, www.who.int/about/bugs_drugs_ smoke_chapter_1_smallpox.pdf, accessed on 13 March 2016. It is estimated that around 300 million people died from smallpox during the twentieth century alone.

10 Biopharmaceutical Research Industry, Biopharmaceutical Research Industry 2016 Profile, www.phrma.org/sites/ default/files/pdf/biopharmaceutical-industry-profile.pdf. 
cent above inflation. ${ }^{11}$ One objective of competition rules should therefore be to encourage $R \& D$ activities.

\section{THE DETERMINANTS OF R\&D INTENSITY IN THE PHARMACEUTICAL INDUSTRY}

1.24 To understand how competition rules may affect innovation, it is helpful to point to the two main factors that determine $R \& D$ investments in the pharmaceutical industry: expected returns on investment and cash flows. We briefly discuss each of them in turn.

1.25 Expected returns

(a) Like any other investment decision, the amount that pharmaceutical companies will invest in R\&D activities depends on their expected returns. In theory, a firm will pursue investment projects only when their expected return is greater than the cost of capital required. This implies that when expected returns increase, holding cost of capital required constant, spending on R\&D will typically go up.

(b) However, against this background, the cost of developing new medicines has been rising steadily. A recent study by DiMasi et al. (2016) based on $\mathrm{R} \& \mathrm{D}$ costs of 106 randomly selected new drugs shows that development costs in the United States have tripled since 2003. ${ }^{12}$ This is explained in large part because the process is becoming lengthier (often taking more than a decade) and failure rates for medicines tested on human subjects have been increasing. In this context, it is important to maintain the level of returns for firms to continue investing.

1.26 Cash flow

(a) Cash flow is another important driver of $R \& D$ intensity. This is because almost all $\mathrm{R} \& \mathrm{D}$ investments in the pharmaceutical industry are selffinanced. ${ }^{13}$ Due to the highly uncertain nature of these investments, they entail enormous risks; as a result, investors request high premiums. In particular, the outcome of $R \& D$ is very uncertain. The chances of isolating a substance with therapeutic value are relatively small, with

11 Joseph DiMasi, Henry G. Grabowski and Ronald W. Hansen, "Innovation in the Pharmaceutical Industry: New Estimates of R\&D Costs" (2016) 47 Journal of Health Economics 20-33.

12 Ibid.

13 OECD, Pharmaceutical Pricing Policies in a Global Market, OECD Health Policy Studies, page 192 (2008). 
several estimates ranging from one in 5,000 to one in 10,000. ${ }^{14}$ Even drugs that have made it to the stage of clinical testing have low chances of being approved. ${ }^{15}$

(b) This is a lengthy process: typically more than ten years pass between the time a pharmaceutical company makes a discovery and the time the medicine is brought to market.

(c) Additionally, the market is characterised by a high degree of asymmetric information: in general, pharmaceutical companies have better information about the likelihood of success and the nature of the research project than outside investors. This makes internal funding relatively more attractive than access to capital markets (i.e., debt or equity financing). In other words, the perceived expected returns are larger to the firm than to outside investors.

(d) Academic research actually confirms that these two drivers, expected returns and availability of cash flows, impact positively R\&D intensity (which is measured by dividing R\&D expenditures with sales). That is, more cash flow and/or higher expected returns translate into more $R \& D$ spending (per every euro of sales). Grabowski and Vernon (2000), ${ }^{16}$ using data from 11 major drug companies over the period 1974-94 show that cash flow is an important determinant of R\&D intensity. Concomitantly, they also find evidence that expected return is another important factor. These findings were corroborated by Vernon (2005) using data from 14 firms between 1994 and $1997 .{ }^{17}$

The pricing of medicines and R\&D spending

(a) Because expected returns and cash flow depend on the (expected) price of medicines, there is an indirect link between pricing and R\&D intensity. That is, higher price levels would lead to more investments, and thus potentially more innovation.

(b) A number of studies suggest that indeed prices affect R\&D spending in the pharmaceutical sector. Giaccotto et al. (2005) estimate the impact of changes in subscription medicine prices on industry-level R\&D intensity

14 European Commission, Pharmaceutical Sector Inquiry, Final Report, 8 July 2009, http://ec.europa.eu/ competition/sectors/pharmaceuticals/inquiry/staff_working_paper_part1.pdf, para. 161, accessed on 17 December 2015.

15 DiMasi, et al., supra note 11 . The probability of being approved, conditional on having entered clinical testing, is in the 10-20 per cent range.

16 Henry G. Grabowski and John A. Vernon, "The Determinants of Pharmaceutical Research and Development Expenditures" (2000) 10(1-2) Journal of Evolutionary Economics 201-15.

17 John A. Vernon, "Examining the Link Between Price Regulation and Pharmaceutical R\&D Investment" (2005) 14(1) Health Economics 1-16. 
in the United States from 1952 to $2001 .{ }^{18}$ They find that a ten per cent increase in the growth of real drug prices is associated with nearly a six per cent increase in the growth of R\&D intensity. Using cross-sectional data, Civan and Maloney (2009) show that when prices are higher prices in a therapeutic category, this is associated with a larger number of drugs in the development pipeline. ${ }^{19}$ Golec and Vernon (2006) directly compare the US and EU markets and find that European consumers enjoyed smaller drug price inflation during 1986 and 2004 but at the cost of 46 fewer new drugs introduced by EU firms. ${ }^{20}$

\section{COMPETITION AND THE PATENT SYSTEM}

1.28 In general, competition leads to lower prices, which benefit consumers. However, prices and R\&D investments tend to be positively correlated, which means that (expected) prices at high levels is likely to generate more innovation than otherwise would be the case.

1.29 Indeed, firms undertake $R \& D$ investments to develop new products, but will do so only if they expect returns that are sufficiently high. ${ }^{21}$ This, in particular, requires that prices be sufficiently high to earn revenue that covers all $R \& D$ fixed costs and yields a competitive return. Innovation is high but so are prices. But, if rivals can copy the innovation, competition will ensue, leading to lower prices and a widespread dissemination of innovation, which would benefit society. The innovator, however, would expect much lower returns, to the point that $\mathrm{R} \& \mathrm{D}$ investments may no longer be profitable. In this case, prices are low but so is innovation.

1.30 The relationship between innovation and prices creates some tension for policy makers. It is not possible to have vigorous competition pushing prices to the bottom, while at the same time expect firms to heavily invest in R\&D. There is a clear trade-off, and government may need to balance the benefit that arises from short-term competition (low prices and massive consumption)

18 Carmelo Giaccotto, Rexford E. Santerre and John A. Vernon, "Drug Prices and Research and Development Investment Behavior in the Pharmaceutical Industry” (2005) 48(1) The Journal of Law and Economics 195-214.

19 Abdulkadir Civan and Michael T. Maloney, "The Effect of Price on Pharmaceutical R\&D" (2009) 9(1) The BE Journal of Economic Analysis \& Policy Article 15.

20 Joseph H. Golec and John A. Vernon, European Pharmaceutical Price Regulation, Firm Profitability, and RED Spending (2006), National Bureau of Economic Research No. w12676.

21 Investors compare returns, and would always prefer investment opportunities that yield higher return (that is, if two opportunities are equally risky, they would always choose the opportunity that provides the higher return). Hence firms would not pursue R\&D activities if the expected return is too low. 
with the benefit of long-term competition ( $R \& D$ investments that produce new products). To stimulate innovation, it appears necessary to sacrifice short-term competition and thus low prices, at least temporarily. This is what the patent system seeks to achieve. To encourage $R \& D$ investments, intellectual property rights (IPRs) protect originators from competitors that would want to have a free ride and copy the innovation. As a result, patent holders have the exclusive right to exploit their innovation.

The patent system seeks to maintain the balance between these two opposite effects. By granting patent holders exclusivity rights to exploit their innovation, the patent system prevents other firms from free-riding on the investments of those who carry the load of R\&D activities, thereby limiting competition while allowing innovators to charge "monopoly" prices. In principle during this period of exclusivity investors have sufficient time to recoup their investments. After 20 years the patent falls into the public domain, and anyone can legally copy the innovation. Typically, at that moment the successful innovation becomes cheaper (as anyone can legally produce it), and thus widespread. The patent system therefore promotes innovation by initially granting exclusivity and later its dissemination at lower prices by removing the exclusivity and making the innovation freely available. Limiting or prolonging the period of exclusivity would alter this trade-off and the welfare effects would need to be carefully weighted.

This classic trade-off applies to the pharmaceutical industry, although it is exacerbated by the sheer importance of innovation in this sector. As indicated above the pharmaceutical companies invest large sums to develop new treatments. Investing in the search of new medicines is not only a risky venture-it often fails-but it is also a lengthy and costly process. Nevertheless, pharmaceutical companies have continued to invest because they benefit from the temporary exclusive rights to exploit their innovations bestowed by the patent system. While holding a temporary "monopoly" position, pharmaceutical companies may obtain a sufficiently high price on the supply of successful medicines to recoup their initial investments and also amass enough cash to fund ongoing and future investments. In fact, for many pharmaceutical companies, the bulk of their revenues are derived from a few blockbuster drugs, which serve to finance their entire $R \& D$ activities. ${ }^{22}$

The patent system gives pharmaceutical companies exclusivity for 20 years from the date of filing. However, it takes many years to develop medicines

22 European Commission, supra note 14, Table 2. As much as 55 per cent of global turnover may be generated by a single blockbuster medicine. 
after the patent has been filed. This lengthy process involves several development phases, including notably a pre-clinical development phase and then, if successful, a long period of clinical trials. Only when that stage has passed, the drug originator can apply for a marketing authorisation. All in all, it often takes more than ten years between the time the patent on the molecule is filed and when the medicine reaches the market. ${ }^{23}$

1.34 The relatively short period of effective exclusivity that pharmaceutical companies enjoy selling medicines may be considered a handicap. It reduces the return of investment and limits the accumulation of cash flow. Because the pharmaceutical industry finances its own $R \& D$ investment, by construction, this limits the industry's ability to fund future research. To address this issue, a Supplementary Protection Certificate has been introduced in the European Union. To ensure that medicines have a long-enough exclusivity timespan, the certificate ensures up to five additional years of protection. Importantly, the total period of exclusivity, starting from the marketing authorisation of the product, cannot exceed 15 years. ${ }^{24}$

\section{DELAYING THE ENTRY OF GENERICS}

1.35 As set out above, there is tension between the short-term benefit brought by price competition and the long-term positive effect of product innovation on welfare. In sectors where innovation is important, finding the right balance between these two effects is critical.

1.36 Once a patent expires in the pharmaceutical industry, generic companies launch, boosting competition by cutting prices substantially. A generic medicine is a copy of the originator drug; that is, it has the same active pharmaceutical ingredient, and is thus in principle a perfect substitute. Generic companies have to obtain a marketing authorisation, through filing an "abridged application", which only needs to prove that their product is bioequivalent ${ }^{25}$ to a previously authorised medicine-typically that of the

23 European Federation of Pharmaceutical Industries and Associations, supra note 2.

24 Council Regulation (EEC) No 1768/92 (18 June 1992) concerning the creation of a supplementary protection certificate for medicinal products, http://eur-lex.europa.eu/LexUriServ/LexUriServ.do?uri= CELEX:31992R1768:EN:HTML.

25 European Medicines Agency, Guidelines on the Investigation of Bioequivalence (2010), www.ema.europa.eu/ docs/en_GB/document_library/Scientific_guideline/2010/01/WC500070039.pdf, accessed on 18 April 2016. "Two medicinal products containing the same active substance are considered bioequivalent if they are pharmaceutically equivalent or pharmaceutical alternatives and their bio availabilities (rate and extent) after administration in the same molar dose lie within acceptable predefined limits." 
originator. ${ }^{26}$ Generic companies can slash prices because they spend less on R\&D, they incur smaller other fixed costs (promotion, branding, etc.), and their main cost is manufacturing. ${ }^{27}$

The benefits of price competition after a generic launch are well documented. Following the sector inquiry, the European Commission underscores the benefit of competition by generic medicines, which contributes to reducing medicine prices substantially. In particular, this effect benefits public budgets (including health care expenditures), keeping them under control while ensuring widespread access to medicines. ${ }^{28}$

Competition authorities have been concerned that pharmaceutical companies may engage in practices that seek to prolong the exclusivity period of patented drugs, thereby altering the terms of the trade-off set out by the existing legal system. Specifically, in the final report of the sector inquiry, the European Commission found that originator companies have had recourse to various tactics to delay entry of generics. By stifling generic competition and unduly extending their protection, pharmaceutical companies allegedly harm the economy.

However, in light of the trade-off described above, the effects of the practices that we present below may be ambiguous. This is because, even if these practices limit price competition (some clearly more than others), by allowing pharmaceutical companies to continue reaping "monopoly" rents, at the same time, any additional cash flows may help financing future research, notably in light of rising cost. ${ }^{29}$ In this context, a strict application of competition rules without having regards to long-term benefits of innovation may be short-sighted.

26 European Commission, supra note 14, para. 322.

27 Ibid, page 40.

28 European Commission, Communication from the Commission, Executive Summary of the Pharmaceutical Sector Inquiry, Final Report, http://ec.europa.eu/competition/sectors/pharmaceuticals/inquiry/communication_en.pdf, page 8, accessed on 18 December 2015:

the price at which generic companies enter the market was, on average, $25 \%$ lower than the price of the originator medicines prior to the loss of exclusivity. Two years after entry, prices of generic medicines were on average $40 \%$ below the former originator price. Also the prices of originator products appear to drop following generic entry. The market share (in volume terms) of the generic companies was about $30 \%$ at the end of the first year and $45 \%$ after two years. In other words, any delay will have a significant cost/revenue impact.

29 DiMasi, et al., supra note 11. Using data from 106 randomly selected new drugs, DiMasi et al. show that the cost of developing drugs has increased over time. 
1.40 Below we briefly introduce some of the practices that may potentially stifle competition from generic companies.

\section{A. Strategic use of the patent system}

1.41 Competition authorities have been concerned that originators may seek to game the patent system to prolong the exclusivity period. Indeed, while patents provide a protection against the free-riding of non-innovators, they can also provide the means to hamper competition. As highlighted, inter alia, by Lemley and Shapiro (2005), all patents are not equal: some are more likely to be valid—upheld in court-than others. ${ }^{30}$ This implies that even so-called "weak" patents, if not challenged, would prevent generic entry. The Commission highlights a number of strategies, related to patents, that pharmaceutical companies may use to keep generic medicines out of the market.

1.42 One such strategy is to file patents related to ancillary characteristics of an already patented product, which should expire as late as possible after the end of the base patent(s). Hemphill and Sampat (2012) report that one antidepressant had as much as ten such patents, which would have extended its protection for 16 years had it not been for a successful challenge. ${ }^{31}$ These are sometimes called "patent clusters" or "patent thickets". ${ }^{32}$ The practice is not problematic if the patents cover real innovations; if, on the other hand, the patents are weak and numerous, they may succeed in extending protection even though they rest on dubious claims. The reason why even weak patents may succeed in lengthening the protection is that challenging them is akin to a "public good": if one generic supplier succeeds in overturning the patent, all other generic suppliers will benefit without incurring any cost, free-riding therefore on the efforts of the challenger. In this context, none of the suppliers will actually challenge the patent unless they can coordinate to share the costs, which appears unlikely. ${ }^{33}$

30 Mark A. Lemley and Carl Shapiro, "Probabilistic Patents" (2005) 19(2) Journal of Economic Perspectives 75-98; Carl Shapiro, "Antitrust Limits to Patent Settlement" (2003) 34(2) RAND Journal of Economics 391-411, page 395:

What the patent grant actually gives the patent holder is the right to sue to prevent others from infringing the patent. Nothing in the patent grant guarantees that the patent will be declared valid, or that the defendant in the patent suit will be found to have infringed. In other words, all real patents are less strong than the idealized patent grant usually imagined in economic theory.

31 C. Scott Hemphill and Bhaven N. Sampat, "Evergreening, Patent Challenges, and Effective Market Life in Pharmaceuticals" (2012) 21(2) Journal of Health Economics 327-39.

32 European Commission, Final Results of the Commission Pharmaceutical Sector Inquiry: Competition and Regulatory Concerns to Address, Competition Policy Newsletter, No. 3 (2009), http://ec.europa.eu/ competition/publications/cpn/cpn2009_3.pdf.

33 See Lemley and Shapiro, supra note 30. 
Another strategy concerns agreements to settle a patent dispute but include a so-called "reverse payment". This occurs when the originator pharmaceutical company, as part of a settlement agreement, transfers "value" to the generic company, either via a straight cash payment or through a distributor agreement. ${ }^{34}$ Although settlement agreements are generally viewed positively since they avoid a lengthy judicial process, reducing both congestion in courts and legal costs, "reverse payment" settlements may actually prolong the exclusivity period for the benefit of the originator and at the expense of consumers, at least in the short term. Competition authorities, notably the US Federal Trade Commission and the European Commission, tend to view these agreements as cartel arrangements in which the originator shares part of the monopoly rent with potential competitor(s). However, upon closer inspection, not all agreements with a reverse payment necessarily lead to a restriction of price competition. ${ }^{35}$ On the one hand, if the originator pays generic companies to postpone entry because it holds a weak patent, meaning that it would certainly lose a court challenge, in all likelihood entry would be delayed. That is, the originator would expect that without such payment, generic competition would likely start before the patent expires. In this case, the settlement has clear short-term anticompetitive intent and effects. On the other hand, even though the patent holder has a strong patent, it may prefer settling the dispute, avoiding the risk of losing the court challenge. One reason why the originator pays the generic company is due to risk aversion, which weakens its bargaining position. Because pharmaceutical companies often depend on the revenue from one or two blockbuster medicines, losing in court could have detrimental effects on their ability to finance future research. Even if it is likely to win in court, the originator does not want to take any risk because of the potentially huge financial loss that this may entail. ${ }^{36}$

Interestingly, the strategy of "paying" generic companies to delay entry appears much more expensive in the EU than in the United States. This is due to

34 In general, the generic company would have to obtain a licence, and potentially pay a royalty to the originator. However, in this case the payment goes from the originator to the generic company, hence the term "reverse payment".

35 See Shapiro, supra note 30.

36 Barry C. Harris, Kevin M. Murphy, Robert D. Willig and Mattew B. Wright, "Activating Actavis: a More Complete Story" (2014) 28(2) Antitrust 83-9.

Economists talk of risk aversion when an individual (or a firm) prefers a sure pay-off to an equivalent, but uncertain, pay-off. For instance, suppose that an originator will earn EUR 100 million if he retains the exclusivity. He would be risk-averse if he preferred to pay more than EUR one million to settle a litigation that has a one per cent chance of overturning its exclusivity. He would be risk-neutral if he agreed to pay only EUR one million and risk-loving if he would pay only less than EUR one million.

Although not related to the pharmaceutical industry, in the dispute between Windows and Lindows, there was a small risk that Microsoft might lose its "Windows" trademark. Rather than take that small but extremely costly risk, Microsoft chose to settle and paid Lindows to change its name. 
legislation in the United States, or at least its interpretation, whereby the first generic firm to obtain FDA approval is granted an exclusivity period of 180 days. ${ }^{37}$ To get the approval, however, the firm must "declare that its product does not infringe the relevant patents or that the relevant patents are invalid", ${ }^{38}$ which typically leads to litigation. Whether or not the first generic company succeeds in challenging the patent, the patent holder can settle with the first entrant on a date of entry, while also guaranteeing the 180 days' exclusivity period. The cost advantage resides in that a settlement with the first generic supplier implies that all other generic companies must wait to enter until the 180 days expire. In short, by settling with the first entrant, the patent holder blocks everyone else. ${ }^{39}$ In the EU, instead, there is no such exclusivity rule and an originator may have to settle with multiple generic firms, hence increasing the cost of "pay for delay" for the originator.

1.45 The European Commission found this practice illegal in three separate cases. ${ }^{40}$ In 2013, the Commission concluded that the settlement between Lundbeck and several generic suppliers delayed entry of cheaper versions of citalopram, an antidepressant, and thus infringed article 101 TFEU. The Commission found that Lundbeck agreed to make a payment, to buy the stock of the generic medicine (to destroy it) and to enter into a distribution agreement which would have benefited the generic supplier. Importantly, the Commission considered the settlement as a "by object" infringement and it therefore did not investigate the effects of the settlement. The decision was appealed before the General Court, which in September 2016 sided with the Commission. ${ }^{41}$

1.46 In December 2013, the Commission fined Johnson \& Johnson (J\&J) and Novartis because of an anticompetitive agreement that delayed entry of a

37 U.S. Department of Health and Human Services, Food and Drug Administration, Centre for Drug Evaluation and Research (CDER), Guidance for Industry: 180-Day Generic Drug Exclusivity Under the Hatch-Waxman Amendments to the Federal Food, Drug and Cosmetic Act (June 1998), www.fda.gov/downloads/ Drugs/.../Guidances/ucm079342.pdf.

38 FTC, Pay-for-Delay: How Drug Company Pay-Offs Cost Consumers Billions (January 2010), www.ftc.gov/sites/ default/files/documents/reports/pay-delay-how-drug-company-pay-offs-cost-consumers-billions-federaltrade-commission-staff-study/100112payfordelayrpt.pdf.

39 C. Scott Hemphill and Mark A. Lemley, "Earning Exclusivity: Generic Drug Incentives and the HatchWaxman Act” (2011) 77(3) Antitrust Law Journal 947-89.

40 Damien Geradin, Douglas H. Ginsburg and Safty Graham, Reverse Payment Patent Settlements in the European Union and the United States, George Mason Legal Studies Research Paper No. LS 15-22 (2015). This situation is also known as a "reverse-payment patent settlement".

41 General Court of the European Union, Judgments in Case T-460/13, T- 467/13, T-469/13, T-470/13, T-471/13, and T-472/13, Press Release No 90/16 (8 September 2016), http://curia.europa.eu/jcms/upload/ docs/application/pdf/2016-09/cp160090en.pdf. On 8 September 2016 the General Court of the European Union dismissed the actions brought by Lundbeck and the generic companies and confirmed the fines of almost EUR 150 million imposed on them. 
cheaper generic version of the pain-killer fentanyl. Janssen-Cilag, a J\&J Dutch subsidiary, concluded a co-promotion agreement with Sandoz, a Novartis subsidiary that was about to launch a generic version of fentanyl. The agreement stipulated that Sandoz in exchange for its cooperation would receive monthly payments, but also it would not launch the generic product. According to the Commission, the payments gave Sandoz strong incentive not to enter the market as these payments exceeded profits that could be expected from selling the generic version. The decision was not appealed.

Finally, Servier and five producers of generic medicines were fined EUR 427.7 million in 2014 by the Commission, which considered that the various settlement agreements among the producers led to the protection of Servier's bestselling blood pressure medicine, perindopril. Specifically, the Commission considered that these agreements consisted of "buying out" potential competitors so that they would not launch their generic version of Servier's medicine. ${ }^{42}$ The General Court upheld the Commission's decision, but the parties have appealed and judgment of the Court of Justice of the European Union is still pending at the time of writing.

\section{B. Product hopping}

Another practice that may potentially delay the entry of generics is "product hopping". ${ }^{43}$ When originators make changes to the composition of their product, such that the new version is not exactly a bioequivalent to the old one, such action may actually block generic entry. This is because the originator withdraws the older version of its product from the market, thereby forcing patients to switch to the new one. When the generic companies enter, however, they cannot compete to the same extent with the new version since they are only bioequivalent with the old product. Indeed, doctors and/or pharmacists may not be in a position to propose the generic version to patients. This practice may enable the originator to escape generic competition.

Although this practice surely protects the originator from aggressive price competition, however, the new version of the medicine may also bring about "genuine" therapeutic benefits that the old version did not provide. As a result,

42 European Commission, Antitrust: Commission Fines Servier and Five Generic Companies for Curbing Entry of Cheaper Versions of Cardiovascular Medicine, Press Release Database, 9 July 2014; Commission decision relating to a proceeding under Article 101 and Article 102 of the Treaty on the Functioning of the European Union, Case AT.39612-Perindopril (Servier), 9 July 2014.

43 Jessie Cheng, "An Antitrust Analysis of Product Hopping in the Pharmaceutical Industry" (2008) 108 Columbia Law Review 1471-515. 
the gap between the old and new medicine may be substantial enough that the new one may not be considered a substitute.

1.50 In the UK, in 2011 the OFT found that Reckitt Benckiser Healthcare had abused its dominant position for using such a strategy. Specifically, the OFT concluded that Reckitt withdrew its Gaviscon Original Liquid medicine from the NHS prescription channel after the product's patent had expired but before the publication of the generic name for it, so that more prescriptions would be issued for its alternative product, Gaviscon Advance Liquid. ${ }^{44}$

1.51 In 2005, the Commission concluded that AstraZeneca abused its dominant position by deregistering a version of Losec, a proton pump inhibitor and a very successful medicine, used for gastrointestinal-acid-related diseases, to delay entry of its generic version. Specifically, the Commission considered that the withdrawal from the market of Losec capsules in Denmark, Norway and Sweden, whilst AstraZenaca was launching Losec tablets, had the objective of delaying entry of competitors. Indeed, by deregistering Losec capsules, AstraZeneca removed the reference market authorisation on which generic firms and parallel traders could rely to enter the market. The Commission found that this move was part of a strategy to delay the market authorisation of generic companies, which were going to launch capsules. ${ }^{45}$

\section{Disparaging the generic version}

1.52 The originator companies may use other practices to delay or limit the scope of generic entry, notably by challenging the bioequivalence of the generic version, thereby undermining its reputation.

1.53 In the final report of the sector inquiry, the European Commission found instances where the originator companies claimed that generic medicines are less safe, less effective and of inferior quality. In particular, originators lobbied national marketing authorisation bodies, which resulted in prolonging of the

44 Decision of the Office of Fair Trading: Abuse of a dominant position by Reckitt Benckiser Healthcare (UK) Limited and Reckitt Benckiser Group plc Decision No. CA98/02/2011 Case CE/8931/08, 12 April 2011, https://assets.publishing.service.gov.uk/media/555de4bbe5274a7084000156/rb-decision.pdf.

45 Commission Decision relating to a proceeding under Article 82 of the EC Treaty and Article 54 of the EEA Agreement, Case Comp/A. 37.507/F3 - Astra Zeneca (15 June 2005), http://ec.europa.eu/competition/ antitrust/cases/dec_docs/37507/37507_193_6.pdf. The Commission also considered that AstraZeneca provided misleading information in a number of Member States (before patent offices and national courts) when applying for extra protection for omeprazole, the active substance of Losec. Originators may extend the protection by applying for supplementary protection certificates (SPCs), whereby the basic patent protection for active substances in medicines can be extended by a maximum of five years. 
authorisation procedures. The Commission estimated that in these cases, the process took an additional four months.

Originator companies may also organise information campaigns targeting decision makers, such as doctors who prescribe medicines and pharmacies who dispense the medicine. The objective of these campaigns is to question the bioequivalence of the generic version, thus casting doubt on their efficacy, and even in some cases their safety. The French Competition Authority fined Sanofi-Aventis and Schering-Plough EUR 40.6 and EUR 15.3 million respectively in two different decisions, notably for abusing their dominant positions. In each case, the Authority concluded that the originator ran a campaign to discourage doctors to prescribe and pharmacists to dispense rival generic versions. In the case of Sanofi-Aventis, the Authority considered that representatives of the drug originator visited doctors and pharmacies to cast doubt on the efficacy of a generic version of Plavix ${ }^{\circledR}$, which is used to treat complications from atherothrombosis. In the case of Schering-Plough, the Authority found that the originator had a plan against a generic version of Subutex ${ }^{\circledR}$, a medicine for the treatment of opiate addiction. The plan was to spread an alarmist message to doctors and pharmacists on the risks of prescribing or dispensing a generic version supplied by Arrow, even though Schering-Plough had no evidence to justify this position.

\section{THE EFFECTS OF PARALLEL TRADE}

In a nutshell, parallel trade is defined as the activity of reselling a product that is protected by intellectual property (IP) in another country without the consent of the IP owner. In some countries, and notably the United States, parallel imports of patent protected medicines are illegal. However, within the EEA, parallel trade is legal, albeit regulated. ${ }^{46}$ The IP protection is exhausted, that is, patent holders have no control of the resale of their products within the EU after the first sale. This implies that after an originator sells the prescription medicine in a Member State that medicine can in principle be resold in any other Member State within the EEA.

In practice pharmaceutical companies can do little to prevent parallel imports within the EU. First, because of price control, notably in low-price countries, they cannot raise prices, and close the gap in the price differential to reduce the incentive of distributors to re-export medicines in high-price countries.

46 Within the single market, there are no legal barriers to trade for distributors. The only requirement is a Parallel Import Product Licence. 
1.57 Other practices that seek to limit parallel trade have been deemed to contravene EU competition rules. One approach that circumvents domestic price control consists of setting up a dual pricing system in low-price countries, whereby distributors pay a higher price for medicines that are re-exported. This pricing policy, however, is a breach of competition law. GlaxoSmithKline (GSK) applied a dual price system so that wholesalers in Spain had to pay higher prices for medicines they intended to export to countries with higher prices than for medicines to be sold domestically. This way parallel traders would not undermine GSK revenue in high-price countries, notably in the UK. Specifically, that system lowered the incentive of Spanish wholesalers to re-export GSK products. This measure, according to the European Commission, restricted competition under Article $101 \mathrm{TFEU}$, as it runs contrary to the goal of EU market integration, and the principle of free movement of goods. One of the objectives of the EU Treaty is the creation of a single market, without any trade restriction. As a result, when firms' control over their distributors also hampers trade between Member States, these practices are often deemed illegal. The Court of Justice, however, considered that the special characteristics of the pharmaceutical market might have warranted an exemption under Article 101(3) TFEU, ${ }^{47}$ which the Commission had not investigated. 48

1.58 Alternatively, pharmaceutical companies may attempt to reduce supply in the low-price country, a move that could be costly in terms of revenue and that may also trigger an investigation for abuse of dominant position. In November 2000 GSK stopped meeting the orders of the Greek wholesalers who bought medicines for distribution in Greece and export to other Member States. The wholesalers sued GSK, and eventually the Court of Justice affirmed that a pharmaceutical company is abusing its dominant position if it refuses to meet the ordinary orders with the objective of preventing parallel trade.$^{49}$ Nevertheless, the Court considered that pharmaceutical companies must be in a position to protect their own commercial interests if they are confronted with orders that are out of the ordinary.

47 Consolidated version of the Treaty on the Functioning of the European Union [2008] OJ 115, (9 May 2008) P. 0088 - 0089. http://eur-lex.europa.eu/legal-content/EN/TXT/HTML/?uri=CELEX:12008E101\&from= en. See Article 101(3) TFEU.

48 Judgment of the Court of Justice, C-501/06P - GlaxoSmithKline Services and Others v. Commission and Others, paras 104 and following (6 October 2009), http://curia.europa.eu/juris/document/document.jsf;jsessionid= 9ea7d0f130d57c0d28d737704035b579fb09400f37d4.e34KaxiLc3eQc40LaxqMbN4Oc3iSe0?text=\&docid=7 7866\&pageIndex $=0 \&$ doclang $=E N \&$ mode $=1$ st $\&$ dir $=\& o c c=$ first $\&$ part $=1 \& c i d=849725$, accessed on 17 December 2015.

49 Press Release No 65/08, Judgment of the Court of Justice in Cases C-468/06 to C-478/06, Sot.Lélos kai Sia EE and Others v. GlaxoSmithKline AEVE Farmakeftikon Proïonton (16 September 2008). 
Although the legal debate on parallel trade of prescription medicines appears to be settled in Europe, its economic impact on pharmaceutical markets in the EEA is not clear cut. To date, there is no compelling evidence that parallel trade has led to a reduction in the price of prescription medicines, whilst there might be a risk that this activity undermines innovation.

\section{A. The development of parallel imports in the EEA}

As parallel trade is legal in the EEA, traders have had the opportunity to take 1.60 advantage of significant cross-national price differences to resell prescription medicines from low-price to high-price countries.

In spite of the single market objective, the supply of pharmaceutical products is separated into national markets, with the consequence that the same medicine is sold at very different prices. Kanavos and Costa-Font (2005) report price differences of many pharmaceutical products and country pairs of between 100 per cent and 300 per cent. Prices are highest in countries such as Germany, the United Kingdom, the Netherlands and Denmark..$^{50}$ This is due to an array of factors, notably different national regulation and the existence of separate national health insurance systems, which leads pharmaceutical companies to negotiate prices of prescription medicines with individual national health regulators. The outcome of the negotiation typically results either in a price ceiling or in a price formula that applies in the country but not outside. At the end of the day, these bilateral negotiations lead to different price levels across Member States for the same medicine. ${ }^{51}$

Distributors of pharmaceutical products can take advantage of the significant price differentials within the EEA. Parallel imports consist of medicines that are bought by "traders" in a low-price country, re-packaged, re-labelled and then distributed in a high-price country. In fact, distributors in low-price countries, who are authorised to sell there, can ship the medicine without the authorisation of the manufacturer in high-income countries.

In general, export countries are located in Eastern and South Eastern Europe (Greece, Hungary, Romania, Bulgaria, Italy, Spain and Portugal) and import

50 Panos Kanavos and Joan Costa-Font, "Pharmaceutical Parallel Trade in Europe: Stakeholder and Competition Effects” (2005) 20(44) Economic Policy 751-98.

51 The introduction of reference pricing, which consists of determining price level on the basis of a basket of similar medicines (or the same ones), in other countries may contribute to price convergence in the EU. 
countries are in the North (Germany, Great Britain, Sweden, the Netherlands, Denmark, Ireland, Norway and Finland). ${ }^{52}$ All in all, parallel imports represent a substantial share of sales in some high-price countries. EFPIA estimates that in 2014 the share of parallel imports was 25.2 per cent in Denmark, 18.7 per cent in Sweden, 10.6 per cent in the Netherlands, 10.3 per cent in Germany, 7.9 per cent in the UK and seven per cent in Ireland. ${ }^{53}$

1.64 The activity of parallel imports has been encouraged by governments in high-price Member States. In the UK, the Netherlands and Norway, pharmacists have been given a financial incentive to dispense cheaper, imported prescription medicines. For example, in the UK or the Netherlands, pharmacists earn part of the savings that accrued from using parallel imports instead of locally sourced medicines. ${ }^{54}$ In Denmark, Sweden and Germany, pharmacists are compelled to inform patients that cheaper parallel imports are available.

\section{B. The effect of parallel imports on prices}

1.65 In principle, parallel imports of prescription medicines are expected to lower prices in high-price countries. This is because distributors in low-price countries, who act as arbitrageurs, re-export the medicine at a discount, and they will continue to do so until there is no longer a profit to be made, which in theory is the case when the price between the two countries reaches the same level. In practice, this does not happen in part because "traders" incur some costs, notably for distributing and packaging the medicines in the high-price countries. Nevertheless, distributors in low-price countries have an incentive to supply high-price countries if the price differential covers also the cost of re-exporting medicines.

1.66 As indicated above, the price difference that prevails across countries in the EEA is the result of negotiation with a national government. In economics, when a product is sold at a different price without cost justification, this is called "price discrimination". This describes a situation where firms charge different prices for the same product to different customers. Price discrimination arises when the firm can take advantage of the fact that a well-identified customer group is willing to pay more for the product in question than other

52 Florian Scholz, Heinz-Werner Schulte and Frank Weißenfeldt, Parallel Trade: Which Factors Determine the Flow of Goods in Europe?, IMSHEALTH (2015).

53 European Federation of Pharmaceutical Industries and Associations, supra note 2.

54 Margaret K. Kyle, "Parallel Trade in Pharmaceuticals: Firm Responses and Competition Policy", in International Antitrust Law E Policy (2009), Juris Publishing for the Fordham Competition Law, edited by Barry Hawk, Chapter 13. 
customers. Assuming it is able to do so, the firm can then charge a higher price to the group of customers with strong product preference, while setting a lower price for others. In the case of prescription medicines, the price is typically higher in high-income countries, as payers there are willing to pay more.

The practice of price discrimination has two potential positive effects. First, by setting different prices to different customer groups, this strategy allows firms to expand revenue and gross profit, enabling them to repay fixed cost investment; a feature that is pertinent in the pharmaceutical sector. ${ }^{55}$ Second, although some customers pay more while others pay less, the overall impact on consumer welfare can be positive as the firm serves customers who would otherwise not be able to afford the product in question. ${ }^{56}$

Price discrimination is effective only when arbitrage between customer groups is not possible. That is, low-price customers cannot resell the product in question to high-price customers. Parallel imports are a form of arbitrage, which in principle should lead to prices of prescription medicines converging within the EEA, notably by pushing down prices in high-price countries. Although parallel imports are expected to result in lower prices in some countries, in principle they may not necessarily have a positive impact on welfare. ${ }^{57}$ As Malueg and Schwartz (1994) show, when there are large differences in demand across countries, firms may stop supplying low-price countries, and in this case parallel trade reduces consumer welfare. The legality of parallel imports therefore poses a risk that pharmaceutical companies may not supply expensive medicines in low-price countries.

Because arbitrage is expected to reduce prices, parallel imports are often welcome in countries where the government is concerned by the affordability of medicines. However, the available empirical evidence suggests that parallel imports in the pharmaceutical markets do not necessarily lead to price reductions for the benefit of health insurance. ${ }^{58}$ For example, Kanavos and Costa-Font (2005) show that medicines that are re-exported in high income

55 Hal R. Varian, "Price Discrimination", in Handbook of Industrial Organization, Vol. 1 (1989), edited by Richard Schmalensee and Robert Willig, Elsevier, 597-654. Varian argues that Stigler's definition of price discrimination is more accurate since a firm could charge different prices for the same goods because of logistic/transport cost. Stigler's definition can be summarised with the following example. If a hard-cover book sells for $\$ 15$ and the same book costs $\$ 5$ in paperback, there is a presumption of price discrimination as the difference in cost (binding costs) is not enough to explain the price difference.

56 Jean Tirole, Industrial Organization (1988), MIT Press, 185.

57 See David A. Malueg and Marius Schwartz, "Parallel Imports, Demand Dispersion, and International Price Discrimination" (1994) 37(3-4) Journal of International Economics 167-95.

58 European Commission, Competitiveness of the EU Market and Industry for Pharmaceuticals: Volume I, 2009. See page 95 onwards for a comparison of many empirical studies. 
countries do not contribute to lower prices. This is because prices of medicines are largely regulated, and thus any profit that is generated from arbitrage actually benefits parallel traders (and other parties in the distribution chain, for example pharmacists). ${ }^{59}$ Kanavos and Vandoros (2010) examine prices of 19 drugs between 1997 and 2002 in six high-price countries, namely Denmark, Germany, the Netherlands, Norway, Sweden and the UK, in which parallel trade is encouraged as a way to introduce more competition. ${ }^{60}$ Their results indicate that parallel trade has no impact on the retail price of drugs in these countries. Kyle et al. (2008) compare price dispersion of more than 1,000 medicines in 36 therapeutic categories between EU countries, where parallel imports are legal, and countries where they are not. ${ }^{61}$ Their results show that the legalisation of parallel trade has had no effect on prices in Europe. They note, however, that in Europe patients are typically not very price sensitive whilst in most countries pharmacists have no incentive to substitute cheaper versions of the prescription medicines. As a result, both patients and pharmacists might not respond to the introduction of cheaper imports. Conversely, Duso et al. (2014) in a study that focuses on 700 anti-diabetic drugs sold in Germany find that parallel imports decrease the average price of patented medicines by 11 per cent but have had no effect on prices for generic versions. ${ }^{62}$

\section{The effect of parallel imports on innovation}

1.70 By reducing the profit of pharmaceutical companies in high-price countries, parallel imports can be expected to undermine their ability and incentive to invest, leading therefore to fewer innovations and ultimately reducing welfare.

59 See Kanavos and Costa-Font, supra note 50. The authors empirically estimate the effects of pharmaceutical parallel trade in the EU and find (page 752):

that the gains from parallel trade accrue mostly to the distribution chain rather than to health insurance and consumers. This is because in destination countries parallel traded drugs are priced just below originally sourced drugs. We also test to see whether parallel trade has a competition impact on prices in destination countries and find that it does not. Such competition effects as there are in pharmaceuticals come mainly from the presence of generics. Accordingly, instead of a convergence to the bottom in EU pharmaceutical prices, the evidence points at 'convergence to the top'. This is explained by the fact that drug prices are subjected to regulation in individual countries, and by the limited incentives of purchasers to respond to price differentials.

60 Panos Kanavos and Sotiris Vandoros, "Competition in Prescription Drug Markets: is Parallel Trade the Answer?” (2010) 31(5) Managerial and Decision Economics 325-38.

61 Margaret K. Kyle, Jennifer S. Allsbrook and Kevin A. Schulman, "Does Reimportation Reduce Price Differences for Prescription Drugs? Lessons from the European Union” (2008) 43 Health Services Research 1308-24.

62 Tomaso Duso, Annika Herr and Moritz Suppliet, "The Welfare Impact of Parallel Imports: A Structural Approach Applied to the German Market for Oral Anti-Diabetics" (2014) 23(9) Health Economics 1036-57. 
However, this conclusion may be reversed when the regulator in the low-price country adjusts its policy when parallel trade is authorised.

Several academic studies, on the basis of formal economic modelling, highlight the risk that as parallel trade erodes profit of pharmaceutical companies, these companies would invest less in $\mathrm{R} \& \mathrm{D}$, thereby potentially reducing global welfare even though cheaper imports may result in lower prices in the short run. Valletti and Szymanski (2006) and Li and Maskus (2006) show that as parallel trade cuts the profits of pharmaceutical companies, firms' ability and incentive to invest in $R \& D$ falls. Even though parallel imports push prices down, these short-term gains may be easily offset by the long-term loss of innovation. ${ }^{63}$

These studies assume that pharmaceutical companies set prices freely, and in 1.72 this case, liberalisation of parallel trade is always expected to eat some profit. In reality, however, prices of prescription medicines are regulated. More specifically, the price of subscription medicines is the outcome of negotiations between a national regulator and pharmaceutical companies. In particular, in low-price countries, regulators tend to impose a price ceiling that creates a wedge with prices prevailing in other Member States. With parallel trade, regulators in low-price countries may have an incentive to adjust the price ceiling upward, which would act against parallel trade. In this context, it is no longer clear that parallel trade itself causes a reduction in innovation.

Other academic studies have considered the effect of parallel trade in more realistic settings where national regulators set prices. In this case, the regulatory response of the low-price country plays a key role in determining the overall effect of parallel trade on R\&D investments. In particular, if pharmaceutical companies have bargaining power vis-à-vis the low-price country and/or if the low-price country acknowledges the risk of supply interruptions and/or global under-investment in $\mathrm{R} \& \mathrm{D}$, there might not be any reduction in innovation.

Studies have considered the effect of parallel trade in different settings. Given these considerations, the effect of parallel trade on price regulation must be

63 Tommaso M. Valletti and Stefan Szymanski, "Parallel Trade, International Exhaustion and Intellectual Property Rights: A Welfare Analysis” (2006) 54(4) The Journal of Industrial Economics 499-526, and Changying Li and Keith E. Maskus, "The Impact of Parallel Imports on Investments in Cost-Reducing Research and Development" (2005) 68(2) Journal of International Economics 443-55. Neither study considers the case of price regulation but assumes that the price differential between low-price and high-price countries arises from price discrimination. Assuming that regulated price caps in the high-price country can be undermined by cheaper imports (direct) or that competitive pressure leads manufacturers to lower their prices below the cap (indirect), the results apply in both contexts. 
taken into account to evaluate whether pharmaceutical firms' profits are decreasing under parallel trade. For instance, Pecorino (2002) assumes that negotiations between the regulator in the low-price country and a pharmaceutical firm take the form of a Nash bargaining game. ${ }^{64}$ Knowing that parallel trade will diminish its profits in the high-price country, the firm will make fewer price concessions in the negotiations with the low-price country; in other words, it will bargain harder. Subject to the model assumptions (e.g., linear demand), profits will always rise, unless the foreign regulator has all the bargaining power; then prices will remain unchanged.

1.75 Using a more elaborate model, Grossman and Lai (2008) show that with parallel trade the pace of innovation may be faster. This is because the low-price country will alter its policy under parallel trade, and loosen price regulation, allowing the pharmaceutical company to earn more profit. ${ }^{65}$ First, the low-price country runs the risk of not being supplied at all if a firm earns higher profits by selling only in the high-price market. Second, the low-price country is no longer able to free-ride on the contributions made by the high-price country if arbitrage reduces profits in the high-price country through cheaper imports. At the end of the day, the adjustment in regulation has the effect of raising consumer welfare in the high-price country as well as the firms' profits but reducing consumer welfare in the low-price country.

1.76 Bennato and Valletti (2014) reach the same conclusion but emphasise the importance of commitment for the regulator in the low-price country. ${ }^{66}$ If the regulator is unable to credibly commit not to set the price ceiling at marginal cost (so that the pharmaceutical company makes no profit) once $R \& D$ expenditures have been sunk, then we have a classic hold-up situation: the pharmaceutical firm knows that it cannot expect to earn any profit on the low-price market and thus will only serve the high-price country. This reduces consumer surplus in both countries because $R \& D$ expenditures are lower and the low-price country is not served. The regulator in the low-price country will therefore commit not to extract the pharmaceutical company rent, loosening price regulation, which in turn will favour innovation.

64 Paul Pecorino, "Should the US Allow Prescription Drug Reimports from Canada?" (2002) 21(4) Journal of Health Economics 699-708.

65 Gene M. Grossman and Edwin L-C. Lai, "Parallel Imports and Price Controls" (2008) 39(2) The Rand Journal of Economics 378-402.

66 Anna Rita Bennato and Tommaso Valletti, "Pharmaceutical Innovation and Parallel Trade" (2014) 33 International Journal of Industrial Organization 83-92. 
At the end of the day, whether parallel imports undermine innovation in the pharmaceutical industry is an empirical question. In particular, it will depend on the extent to which price regulation is stringent in the exporting countries.

\section{THE DEMAND AND PRICING OF PHARMACEUTICAL PRODUCTS}

The extent to which consumers can substitute to other products is a critical determinant of market power, and thus affects the price level that manufacturers can charge. That is, when firms raise prices and few consumers switch away, prices can be set significantly above cost, and in this case firms hold significant market power. However, when the demand side is made of large and sophisticated buyers, they may be able to resist price increases. When a large sophisticated buyer decides to take its business elsewhere, it can impose a significant loss on its suppliers. Confronted with such a threat, suppliers may be forced to set lower prices. Buyer power is an important aspect in the assessment of competition law investigations. In particular, countervailing buyer power may defeat the price increase of mergers or undermine market power of firms that hold large market shares, suggesting that these firms are not dominant after all. ${ }^{67}$

In the pharmaceutical industry, the demand side has unusual characteristics.

As we will see below, the institutional arrangements play an important role. The millions of separate patients, whose individual demand is negligible, are not actually those who pay for the medicines. Instead, national health insurers act on behalf of a country's residents and negotiate prices with manufacturers. This position should give them enough bargaining strength to undermine the pricing power of originator companies. However, as explained below, the bargaining power of national health insurance might not be as high as one might expect. Furthermore, and perhaps surprisingly, hospitals, which are smaller in scale, often obtain better prices for medicines.

\section{A. Demand for pharmaceuticals: institutional details}

As we explain in this section the demand for prescription medicines appears to

be largely price inelastic (that is, insensitive to price changes), which should confer pharmaceutical companies significant market power.

67 See EC Guidelines on the assessment of horizontal mergers under the Council Regulation on the control of concentrations between undertakings at paras. 64-67, http://eur-lex.europa.eu/legal-content/EN/TXT/ HTML/?uri=CELEX:52004XC0205(02)\&from=EN. 
1.81 The nature of the demand for medicines is similar to that of the overall demand for health care. Individual demand for health care has specific characteristics that make it different from demand for other goods. In particular, individuals' need for health care is irregular and largely unpredictable. Patients acquire medicines to cure illness and restore their health. Not everyone requires the same level of health care, and in many ways illness is often difficult to predict. Importantly, illness is a risk to individuals, affecting-sometimes gravely—-their earning ability. ${ }^{68}$ Like other types of risk, however, it can be insured.

1.82 In Europe, health insurance, which covers individuals for their medical expenses, is in principle statutory. That is, all citizens are in theory covered for the cost of healthcare. The universal coverage is partly driven by the realisation that the individual consumption of health care also provides benefits to others. For example, inoculation against a contagious disease provides protection and clearly generates a private benefit - to the person receiving the inoculation-as well as an external one-to those who are protected from catching the disease because others around him are inoculated. However, few would want to pay for the inoculation only to protect others. In this context, the demand for health care is less than the socially efficient quantity. There are other social considerations as well, and as a result health insurance schemes vary across Member States. Additionally, demand is not always driven by consumer preferences. This is because patients are generally not informed about illnesses, diagnoses and the effectiveness of therapies and medicines. When ill, people go to see a doctor (whether a general practitioner (GP) or a specialist) who prescribes a treatment and the amount of medicines to be consumed. Demand for medicine is thus driven not by what consumers want, but by what patients need to become healthy again, and these treatments and medicines are selected by doctors. As a result, without health insurance the patient may not be willing (or able) to pay for treatment, as these unpredictable expenses may correspond to a significant portion of a household budget.

1.83 Patients do not pay for medicines, or only pay for a portion of them (in many countries, a small co-payment implies that patients bear a portion of the cost). In Europe national health insurances are established by national legislation and insure residents against the cost of health care. In some cases, patients also have complementary insurance, which pays for the portion that the national

68 Kenneth J. Arrow, "Uncertainty and the Welfare Economics of Medical Care" (1963) 53(5) The American Economic Review 941-73. Arrow argues that uncertainty and imperfect marketability of information lead to the absence of some markets for risk-bearing and consequently to a reduction in welfare. This will be recognised to a certain extent by society, and nonmarket social institutions will arise to bridge the gap (pages 946-47). 
scheme does not cover. This implies that neither those who receive the medicines-patients—nor those who prescribe them-doctors-are the ones paying for them. ${ }^{69}$ At best, patients pay a fraction of the price. Unsurprisingly, demand for medicines therefore appears rather price inelastic. As doctors are not the ones paying, even a substantial price increase would not lead doctors to prescribe less or a different medicine, or to diminish consumers' intakes.

\section{B. Countervailing buyer power in the pharmaceutical industry}

Even though patients use medicines, they do not pay for them. Instead, national health insurances pay in their place. Unlike patients who are numerous, national health insurance providers are large organisations that cover, and thus pay for, millions of patients. In this sense, health insurance providers can be considered as "large buyers". In fact, in many European countries, there is a single national insurance. Given their size, these insurance providers may a priori be expected to exert a significant constraint on the price of medicine.

The key issue with buyer power is thus whether the large customers have the ability to resist a price increase. Large buyers who hold significant bargaining power are able to inflict substantial losses on suppliers in the event that commercial negotiations between the supplier and the purchaser were to break down. In this context, suppliers would prefer abiding by the terms proposed by buyers. Ultimately, buyers have strong bargaining power when the harm inflicted to suppliers is larger than what they would suffer in the event that the parties walk away. Specifically, the strength of bargaining power depends on the valuation of the customer's outside option (what the customer would acquire instead of purchasing goods from the supplier in question) and the supplier's own outside option. ${ }^{70}$

69 In economics, the term "moral hazard" refers to situations where one party (e.g., the doctor) makes decisions without having to bear the financial consequences of these decisions. The "principal-agent" problem is one type of moral hazard where the interests of the principal (e.g., the hospital or the national health system) may differ from the interests of the agent (e.g., the doctor), and this hence leads to outcomes that are not favoured by the principal.

70 Both conditions are necessary: for example, many consumers have alternative options (outside options) for buying a product (other suppliers of the same product or other products), but this will not enable them to pay lower prices (at least not substantially). This is due to the fact that sellers generally also have many other outside options (other consumers). So, buyer power must imply that the seller has few outside options.

See Roman Inderst and Greg Shaffer, "Retail Mergers, Buyer Power and Product Variety” (2007) 117(516) The Economic Journal 45-67; Sara Fisher Ellison and Christopher M. Snyder, "Countervailing Power in Wholesale Pharmaceuticals" (2010) 58(1) The Journal of Industrial Economics 32-53; Justus Haucap, Ulich Heishoff, Gordon J. Klein, Dennis Rickert and Christian Wey, Bargaining Power in Manufacturer-Retailer Relationships (2013) DICE Discussion Paper No. 107; Christian Köhler and Christian Rammer, Buyer Power and Suppliers' Incentives to Innovate (2012) ZEW-Centre for European Economic Research Discussion Paper No 12-058; Roman Inderst and Christian Wey, Buyer Power and Supplier Incentives (2003) WZB, Markets and Political Economy Working Paper No. SP II 5. 
1.86 Because of the particular nature of the demand for pharmaceutical products, assessing buyer power in the pharmaceutical industry is somewhat different from the case with suppliers and buyers in other industries. In particular, although the situation varies by country, in Europe typically the price of medicine is negotiated between a national regulator (or the national health insurer) and pharmaceutical companies. ${ }^{71}$ These regulators act on behalf of all residents and thus can be considered as "monopsonists". That is, pharmaceutical companies have no choice but to deal with the national regulator if they wish to sell their products in that particular country. In principle, this position should give the regulator substantial bargaining power. ${ }^{72}$

1.87 Although regulators are expected to hold significant clout over the pharmaceutical industry, the situation is more complex than what it might appear. In particular, regulators do not have direct control over the consumption of medicines. This means that, unlike a large, sophisticated buyer, they cannot credibly threaten to reduce quantity demanded. In fact, consumption of medicines depends largely on doctors who do not typically prescribe therapies and medicines on the basis of price. That is, if prices were to increase, this would not change the doctor's choice. As a professional, the doctor may intrinsically want to give the best care possible, whatever the costs, because (s)he does not face the financial consequences. This particular feature contributes greatly to undermining the negotiating power of regulators.

1.88 In some countries, regulators have attempted to restore some of the bargaining power using entry of generics, which are therapeutically equivalent to the

71 Kai Ruggeri and Ellen Nolte, Pharmaceutical Pricing - The Use of External Reference Pricing (2013) RAND Corporation RR-240-DH.

72 Finance and NHS/Medicines, Pharmacy and Industry Group, The Pharmaceutical Price Regulation Scheme 2014 (December 2013), www.gov.uk/government/publications/pharmaceutical-price-regulation-scheme2014, accessed on 18 December 2015. When negotiating prices, regulators have regard in particular to the therapeutic value of the medicine and in many cases to the price set in other European countries (i.e., external reference pricing). For example, in the UK, prices for prescription drugs in the NHS are set through discussion between the Association of the British Pharmaceutical Industry (ABPI) and the government. The agreement is open to non-members of the ABPI.

OEBIG, Health Economics, Surveying, Assessing and Analysing the Pharmaceutical Sector in the 25 Member States, July 2006. In France and in other countries, medicine prices are negotiated between the government and the industry. As part of these negotiations, the price must be consistent with the prices in the main EU Member States.

Civitas, Healthcare Systems: France, www.digitalezorg.n1/digitale/uploads/2015/03/France-Health-system. pdf, accessed on 18 December 2015 and www.french-property.com/news/french_health/prescription_ medicines_price_information/.

This means that the initial price is not lower than what is observed in Germany, Italy, Spain and the UK.

Civitas, Healthcare Systems: Germany, www.digitalezorg.n1/digitale/uploads/2015/03/germany.pdf, accessed on 18 December 2015; Ruggeri and Nolte, supra note 71, accessed on 18 December 2015. In Germany in principle, medicine prices are determined by the pharmaceutical manufacturers, but they are subject to a complex set of regulations regarding reimbursement, which affects the price that manufacturers can charge. 
originator's product. In these cases, the government imposes on doctors and pharmacists the obligation to prescribe and sell only (the cheapest) generics when possible. Doctors and/or patients may however resist such changes, thereby weakening the negotiating power of government agencies. As doctors are ultimately the ones responsible for the health of their patients, they may be in a position to successfully resist these changes.

In the AstraZeneca decision, the Commission concluded that the negotiation power of regulators is not strong enough to undermine the market power of originator companies. In particular, the outside option of the agencies is rather unattractive when they negotiate the price of new and innovative medicines. They cannot credibly threaten not to authorise new treatments. In more economic terms, the outside option of government agencies is much worse than that of the originator and, hence, abstaining from the trade is more costly for the former than for the latter. Specifically the Commission considers: ${ }^{73}$

arguments about "buyer power" constituting an element conducive to lack of dominance are exaggerated. The health system may negotiate a price for a medicine, but it cannot normally determine the quantity of the medicine that will be bought, as the decision is mainly taken by a third party (normally the prescribing doctors and, to a limited extent, the final consumer). Within the EEA measures are often taken to encourage doctors to prescribe more cost-effective medicines but their effects are often limited ... since the national health system is also entrusted with the responsibility of ensuring the availability of the best medicines in order to protect public health, its bargaining power differs radically between a situation where it negotiates the price of genuinely innovative medicine from a situation where it negotiates the price of line extensions or other products in the same class of medicines. In general the health system cannot simply prevent or unduly delay the marketing of an innovative product through demands which can be perceived to be excessive.

In addition, the Commission considers another factor, which further weakens the position of regulators when negotiating prices with pharmaceutical companies. Governments are cognisant of the fact that originator companies have to reap sufficient profit to continue funding $R \& D$ activities, which are essential to bring new treatment. In the perindopril decision the Commission also relates the absence of buyer power to the objective (of governments) to sustain R\&D: ${ }^{74}$

the public authorities did not effectively react to the entries of cheaper generic versions of other antihypertensive medicines, nor to the fact that Servier were able to steadily increase its absolute profits from perindopril until the arrival of generic perindopril. 
This is understandable, since by intervening the public authorities would risk creating an inter-temporal inconsistency in their policy towards the entire pharmaceutical sector that would potentially be damaging for the general incentives to innovate in that sector ...

1.91 On the other hand, pharmaceutical companies appear to hold some bargaining power. This is because originator companies are global companies, and thus they can always consider not to supply a particular country if they do not consider the terms sufficiently attractive. In AstraZeneca, the Commission considered exactly this point as conducing to the conclusion that the originator had substantial bargaining power given that AstraZeneca did not supply certain countries. ${ }^{75,76}$

1.92 In practice, the bargaining power of pharmaceutical companies varies depending on the size of the market as well as the importance of the medicine at issue. Not selling in one particular country would lower their profit, but this loss might be smaller in comparison to what a country would lose if a particular medicine was not supplied.

\section{In-hospital and out-of-hospital pricing}

1.93 Hospitals purchase medicines directly, which they administer to patients. Because private hospitals, as well as public hospitals, are under budgetary constraints, they seek to cut costs, which gives them an incentive to purchase the cheapest medicine whenever possible.

1.94 As customers, hospitals can exert more buyer power than regulators because hospitals actually have some control over the choice of medicines as well as the quantity they purchase. That is, a hospital can more credibly threaten not to use a particular medicine, or at least reduce its consumption.

1.95 Although the situation varies across countries, increasingly hospitals dictate the choice of medicines and/or medical equipment. That is, the hospital is both the buyer and the decision maker regarding medicines. This means that this segment of the (pharmaceutical) market is generally more competitive than the out-of-hospital segment. That is, even for patented medicines, hospitals may consider different options if the medicines have the same therapeutic use, exploiting competition in earnest. In particular, hospitals

76 AstraZeneca, supra note 45, para. 561; Perindopril, supra note 42, paras 2590-91. 
organise bidding contests for some of their suppliers. ${ }^{77}$ For example, in Germany, hospitals form purchasing groups in order to increase their negotiating power by guaranteeing higher volumes.

Ellison and Snyder (2010) present evidence using US data that having supplier competition is a necessary condition for large buyers to obtain discounts. ${ }^{78}$ Their analysis shows that large drugstore chains receive no discounts for patented medicines relative to small independent chains, a result that can be attributed to the fact that drugstores, whether large chains or small independents, have no control over the choice of medicine nor the quantities since they have to serve consumers who are following their doctors' prescription. In contrast, the results show clearly that hospitals and health maintenance organisations, which can induce doctors to prescribe alternative medicines, obtain significant discounts relative to drugstores even when it comes to patented medicines.

Casual observations suggest that in-hospital prices of medicine are lower than out-of-hospital prices (i.e., medicines bought at pharmacies). ${ }^{79}$ This suggests that hospitals are able to exercise more leverage on originator companies, or in other words that suppliers of medicines have less market power when selling to this segment.

The Napp case in the UK and the AstraZeneca case in the Netherlands hinged on the pricing differential of the same medicine between hospitals and pharmacies. Specifically, the authorities investigated whether the low price charged in the hospital segment was strategic, with the aim to exclude rivals. As in-hospital patients tend to stick to the prescribed medicine once out of the hospital, patients will pay a higher price in the out-of-hospital segment. Interestingly the two investigations ended with different conclusions. In the UK, the OFT fined Napp for excessive out-of-hospital prices, concluding that Napp had a dominant position (a market share of 90 per cent) in the market defined as "the supply of sustained release morphine (MST) capsules and tablets in the UK". 80

77 European Commission, supra note 14, para. 1486. The Commission refers to an OECD study, in which it was concluded that significant savings in the case of purchasing power (through public health insurers) can be realised by tendering systems and if there are multiple sources for the product (like generics).

78 See Ellison and Snyder, supra note 70.

79 Gisela Hostenkamp, “The Market for Hospital Pharmaceuticals in Denmark” (2011) 1(1) Nordic Journal of Health Economics 61-77.

80 Competition Appeal Tribunal, Case No. 1001/1/1/01, para. 152 (15 January 2002), http://webarchive. nationalarchives.gov.uk/20140402142426/http://www.catribunal.org.uk/237-565/1001-1-1-01-Napp-Pharma ceutical-Holdings-Limited-and-Subsidiaries.html accessed on 16 December 2015. 
1.99 In the Netherlands, the inquiry focused on "exclusionary behaviour in hospital". AstraZeneca offered Nexium to Dutch hospitals at a deep discount, whereas patients outside of hospitals had to pay a much higher price when buying the drug at pharmacies. The Netherlands Authority for Consumers and Markets (ACM) suspected that AstraZeneca offered this drug to hospitals at below-cost price in order to make it unattractive for certain generic competitors to enter the market. These generic competitors offer cheaper heartburn drugs (generic versions) outside of hospitals. Patients tend to continue to use the same brand that they had been given in the hospital, and GPs are inclined to prescribe the same brand. ACM suspected that, as a result thereof, AstraZeneca faced little competition. AstraZeneca was thus able to offer Nexium at much higher prices outside of hospitals. This way, the losses incurred by offering Nexium to hospitals at a deep discount could thus be offset. The investigation was closed because the authority could not establish that AstraZeneca held a dominant position in the hospital segment. ${ }^{81}$

1.100 What transpires from these cases is that prices in the hospital segment appear to be more competitive, which is consistent with the observation developed above. That is, hospitals have the ability to influence doctors' decisions and thus have the possibility to switch medicines, thereby imposing constraints on the price charged by the originator companies. The take-away point is that the price differential between in-hospital and out-of-hospital segments indicates that, in the former, originator companies hold less market power, casting doubt on whether they hold any dominant position. This is precisely the conclusion reached by the ACM in the AstraZeneca case.

81 Netherlands Competition Authority, Case No 7069, Summary (24 September 2014), www.acm.nl/en/ publications/publication/13595/No-abuse-of-a-dominant-position-by-AstraZeneca/, accessed on 16 December 2015:

In the legal assessment, ACM first of all faced the question of whether AstraZeneca, with regard to Nexium, enjoyed a dominant position on any market within the meaning of Section $24 \mathrm{Mw}$ and Article 102 TFEU. This was not the case in the hospital market. Yet, in the Statement of Objections, a separate community market had been identified, consisting of users who, due to the spillover effect, were bound to Nexium. The arguments that AstraZeneca put forward regarding, among other aspects, substitution, therapeutic effectiveness and switching behavior of PPI users, have raised reasonable doubts about the conclusion that a group of Nexium users was bound to Nexium through the spillover effect to such an extent and on such a scale that, with regard to this group, AstraZeneca was able to behave independently of its competitors within the meaning of Section $24 \mathrm{Mw}$ and Article 102 TFEU. Taking everything into consideration, ACM comes to the conclusion that, based on the facts at hand, it cannot be sufficiently established that AstraZeneca enjoyed a dominant position on a separate relevant market as defined in the Statement of Objections. 